\title{
Multi-Criterion Assessment of Preferences for Communication Alternatives of Wind Power Park Information System
}

\author{
Antanas NEMURA, Arturas KLEMENTAVIČIUS \\ Laboratory of System Control and Automation, Lithuanian Energy Institute \\ Breslaujos 3, 44403 Kaunas, Lithuania \\ e-mail: antanas.nemura@mikrovisata.net,arklemen@mail.lei.lt
}

Received: February 2007

\begin{abstract}
This paper presents the application of multi-criterion approach to the analysis and comparison of reference alternatives of wind power park information system (WPPIS) which complies with the standard IEC 61400-25. The comparison is based on multi-criterion preferences measured in domination rate (index). The reference alternatives include centralized, mixed and seamless communication topologies. The major features of these alternatives are discussed as well as the multicriterion methodology applied covering pair comparison, Pareto sets and fuzzy sets methods. The current investigation described is an extension of the preceding investigation of the same reference alternatives of WPPIS. As we have showed, the transition from the concerted experts view as it was a case in previous investigation to the conflicting expert views in the current investigation proved the high robustness of solution made for the case of concerted expert views: the rank of preferences for alternatives remained the same, with seamless communication topology on the top the rank.
\end{abstract}

Key words: multi-criterion assessment, wind power park information system, expert view, rank of preferences, communication alternatives.

\section{Introduction}

Following its rapid development in early 1970-ties and subsequent extending practice, the multi-criterion analysis approach as an instrument still finds applications in modern information society and market environment. For instance, there are some research projects under EU 6th Framework Programme related to multi-criterion analysis as CASES (Cost Assessment for Sustainable Energy Systems) project covering, among others, Work Package Methods of Assessment (aimed at review of successful applications of multi-criteria decision analysis in energy and environmental policy making).

Recent development in ICT offered for the wind power sector new types of wind power park's information system (WPPIS). In order to make a well-justified decision for the choice of the most appropiate type, the ranking of market-available systems is a prerequisite. Since WPPIS is specified by both monetary and non-monetary specific parameters (criteria) and these parameters might be viewed with different significance 
degrees (weight factors), the choice of WPPIS can be formulated as multi-criterion assessment problem. The formulation and resolution of such a problem with solutions in form of multi-criterion preferences was presented in (Nemura, 2006).

This problem referred to the situation where the invited experts incidentally expressed concerted (i.e., rather similar) views on a market situation and criteria (parameters) of WPPIS and established the ranks of preferences suitable for decision support.

This paper deals with the conflicting expert views situation where new experts reassess the reference alternatives of WPPIS by bringing forward quite opposite views on the market situation and assessment criteria for WPPIS.

\section{Concept and Major Distinguishing Features of WPPIS}

The prerequisite for a good control and operation of a wind power park (WPP) is adequate information exchanges in the chain Wind Plant - Proxy (local control system) - Client. Proxy mostly means a central server and Client often stands for other control centre (dispatch centre of WPP, of several WPP, of power system). Proxy and client constitute a WPPIS. Beyond this system, the information flows from (to) client to (from) the so-called system actors, i.e., eligible entities related to WPP operation (SCADA and dispatch centres of any power system, monitoring centres, balancing partners within the same virtual power plants). Hereby the client-server architecture seems to be most appropriate for the modern WPPIS. Underlying this architecture is the structure and layout of communication channels between client, proxy and individual logical devices of wind plants. The standard IEC 64100-25 offers the so-called thin client architecture. It means that proxy keeps in storage all the relevant information and provides a range of services for the clients and eligible actors that address it (Fig. 1).

As depicted in Fig. 1, WPPIS comprises 3 distinct models: 1) WPP information model; 2) information exchange model; 3 ) specific mappings to communication protocols (mapping model). The first one, WPP information model, shall be object-oriented and semantically standardized. Within it, the wind turbine generator systems (WTGS)

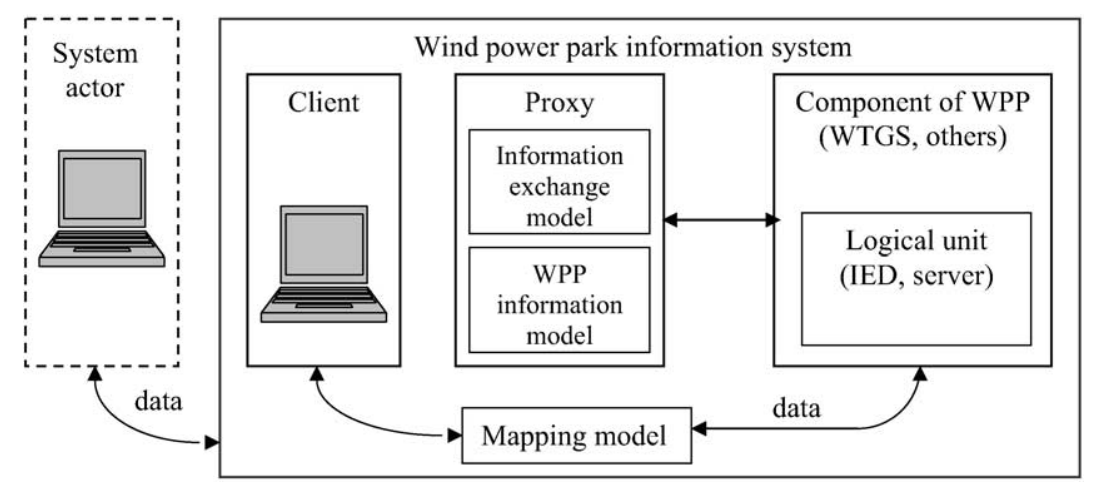

Fig. 1. Concept of a modern wind power park information system in accordance with IEC 61400-25. 
and other WPP components are described by rather abstract models (logical devices) with identification of all their attributes and functionalities which shall be organised to the tree-type hierarchy. A logical device virtually represents a specific constituent of a WTGS (or other component of WPP) that performs a specific function. Each attribute shall have its name and be attributed to a certain type (class), either simple or composite, and shall provide specific information about a WTGS or other component of WPP. This information shall be readily read or changed.

The second one, information exchange model, provides the standardized information flows between a client (or a system actor) and an individual constituent of a specific WTGS or of other component of the WPP (the constituent being represented by the abovementioned logical device). Information exchange model shall cover all proxyprovided services.

The standard IEC 64100-25 stipulates lists of mandatory and optional logical devices. The mandatory list includes WTUR (general wind turbine information), WROT (wind rotor information), WGEN (wind generator information, WGDC (substation information), WYAW (wind yaw information), WMET (meteorological information), WALM (alarm information). The optional list includes WGER (wind gear information), WCNV (converter information), WNAC (wind nacelle information), WTOW (wind tower information), WSLG (wind state logging), WALG (analogous information logging) and WREP (wind reports).

The event logs within the information model are the relevant data sets placed on the time axis. To access a specific log, a client (actor) formulates a filtered query defining the search timescale and search parameters. The logs could be queried for retrieval purposes.

A logical device shall generate and communicate reports entailed by changes of process data, by occurrence of a relevant event as well as periodically. If communication fails (due to interruption), a report of proxy shall be stored in logical device and sent out later.

The combination of first and second models constitutes a client-server interface. This interface allows for the concurrent communication of the proxy (server) with a number of clients (actors), irrespective of their architecture and software applied. The only condition to be met is the compliance of client's (actor's) specific mappings to communication protocols with those of the WPPIS. In other words, the third (mapping) model of WPPIS (Fig. 1) should be compatible with the respective model installed in client's (actor's) server. In addition, a client (actor) shall properly generate the requests, queries and instructions.

The ranking of WPPIS alternatives (by their preferences) in pre-design stage of WPP is based mainly on the differences in this third model. The IEC 64100-25 puts forward 3 alternative communication models of WPPIS. Being peer or similar by the quality of functions fulfilled (transfer of information and of control instructions), these alternatives have some differences emerging from their communication topology.

The 1st alternative (Fig. 2) is qualified as centralized communication topology. It is a modified version of formerly (to date) applied WPPIS. Its backbone is a local control system (LCS). Its proxy communicates through the "pre-standard" interface 1 with the individual intelligent electronic devices (IED) integrated into the WTGS. An IED carries 


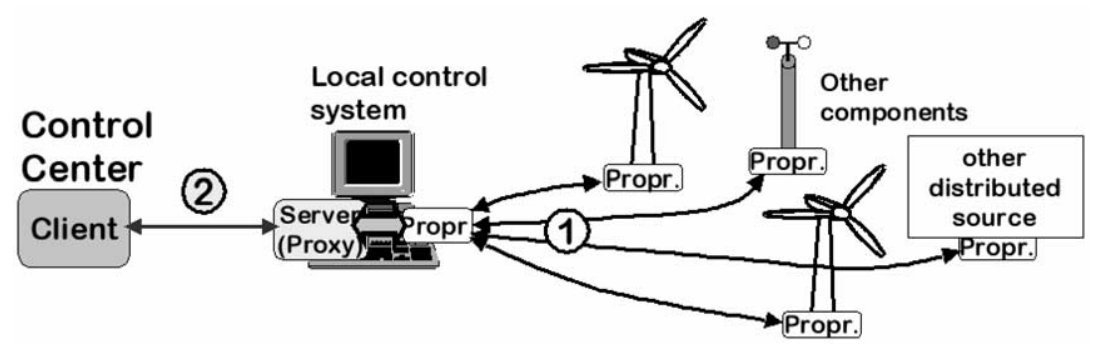

Fig. 2. Centralized communication topology of WPPIS (Propr. stands for proprietary communication protocol).

out the functions of internal supervision of the WTGS constituents, of recording and storage of measurements as well as data sending/receipt to/from external recipients.

Herein "pre-standard" interface 1 means "using proprietary communication protocol" because the communication medium for a IED, the structure of a protocol as well as the semantics of the instructions are established by a manufacturer of WTGS. Therefore a protocol is specific to an individual WTGS.

The pertinence of 1 st alternative to the IEC 64100-25 consists in specification of the interface 2 (Fig. 2). The interface links the LCS (proxy) with the client (actor). The proxy is provided with information procession methods so, as to supply information in the IEC 64100-25 standard-defined way.

The 1st alternative is quite suitable when WTGS of various types with integrated IED are intended for a new or existing WPP. Nevertheless, the diversity of IED brings to some minor encumbrances for the central monitoring and control of WTGS, because the different communication means and semantics types shall be undertaken to access the WTGS. For instance, when a new WTGS is added and its IED doesn't comply with the first and second models of proxy (see Fig. 1), the software of the proxy will be subjected to replacement.

To avoid abovementioned inconsistencies, the centralized topology might be easily transformed to the mixed communication topology (2nd alternative) as depicted in Fig. 3.

The "mixed nature" of 2nd alternative is determined by 2 "mixes": 1) IED and servers under control of the same LCS (proxy) and 2) LCS and router for the access to the same server of WTGS.

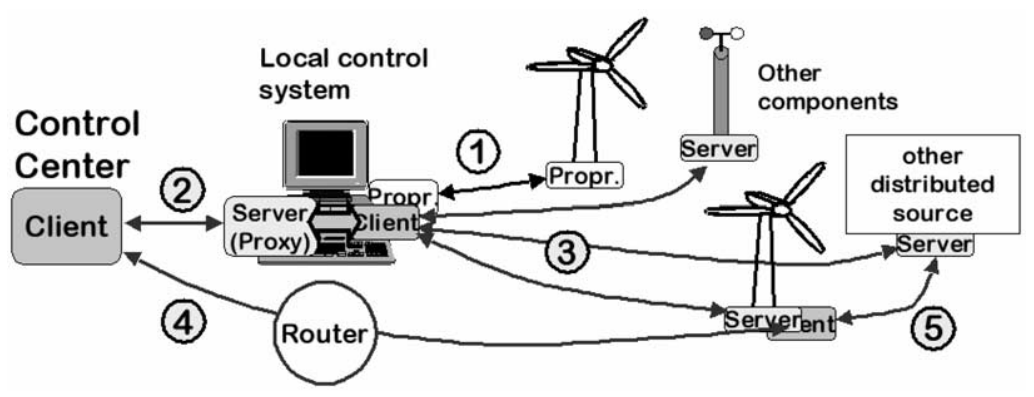

Fig. 3. Mixed communication topology of WPPIS. 
Instead of IED, a new WTGS might be provided with own server linked to the proxy of the existing WPP in the IEC 64100-25 standard-defined way. This linkage is depicted by the interface 3 .

The interface 4 is based on a router that enables the direct access to all the protected logical units. It lends a second communication path ("decentralized path") to a WTGS, parallel to the "centralized path" through the interface 3. Furthermore, there might be another kind of interface 5 which provides direct communication between the different servers of WTGS and operates on a standard protocol.

2nd alternative is a rather advanced structure. It allows for the reserved storage of information procession modules and of information in various places (servers) of WPPIS. The proxy can filter all the information generated in WGTS and performs a number of other information processing functions.

The 3rd alternative (Fig. 4) is qualified as seamless communication topology. Its backbone is a common router for all logical units. This router links both LCS and the alonestanding WTGS (as well as other components of WPP) to a client (actor).

In general, as presented in (Nemura, 2006), technical experts consider the 1st alternative to have the least implementation cost (for a new WPP) but the biggest annual O\&M (operation and maintenance) cost, with availability of WPPIS being lower than that of other alternatives. Considering the 3rd alternative, the experts emphasize its highest availability and the lowest annual O\&M. Its implementation cost is approached to that of the 2 nd alternative. The availability of the latter seems to be better as compared to the 1 st alternative.

As laid down by The Procedure for Promotion of Generation and Purchase of Electricity from Renewable Energy Sources (2006), there are 6 zones of wind turbines connection to the grids in Lithuania, with target $200 \mathrm{MW}$ of total installed capacity in 2010.

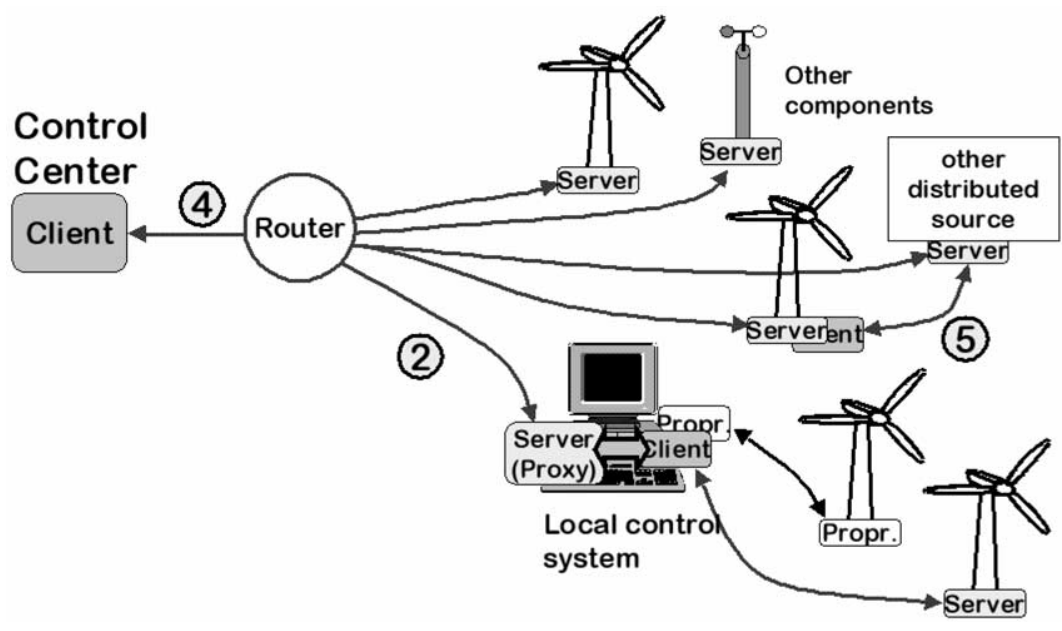

Fig. 4. Seamless communication topology of WPPIS. 
For the purposes of both preceding investigation (Nemura, 2006) and current investigation (presented in this paper), the reference WPP might be the Juknaičiai park, planned to be erected by Juknaičiai locality, Šilute region. The park comprises 44 WTGS of the same type, each capacity of $0.85 \mathrm{MW}$, totaling to $37.4 \mathrm{MW}$. Major technical characteristics are as follow: 1) type of WTGS - V52 (manufacturer - VESTAS company); 2) diameter of wind turbine $-52 \mathrm{~m} ; 3$ ) number of turbine blades -3 ; 4) regulation of output power - by Pitch/OptiSpeed system; 5) minimum wind velocity $-4 \mathrm{~m} / \mathrm{s}$; 6) nominal wind velocity $-16 \mathrm{~m} / \mathrm{s}$; 7) maximum wind velocity $-25 \mathrm{~m} / \mathrm{s}$; 8) generator type - asynchronous (with embedded OptiSpeed system); 9) nominal frequency $-50 \mathrm{~Hz}$; 10) nominal voltage - 690 V. Regulation system is capable to follow a wind velocity and accordingly change the turbine pitch by wind velocities above the nominal rate. Such a capability ensures the continuous and steady output of power. The OptiSpeed system allows the generator to run without consumption of reactive power and with divergence of rotor speed and generator speed up to even $60 \%$. The WTGS is stopped automatically when wind velocity drops below the minimum value or rises above the maximum value.

\section{Methodology of Investigation of Reference WPP}

\subsection{Model Applied}

Assuming the reference WPP as described above, 3 communication alternatives of WPPIS (centralized, mixed and seamless) have been analysed (Nemura, 2006) with multi-criterion analysis model MKO1_VEPIS_44 based on aggregation of 3 analysis methods - pair comparison, Pareto sets and fuzzy sets (Dzemyda, 1994). Therein a criterion is reckoned as a dual parameter having both natural and utility values, the latter being a normalized equivalent of natural value. Natural values are measured in economical, physical dimensions (and some in relative units) while the utility values - in dimensionless units. The same set of criteria is applied in both preceding and current (section 4) investigations: 1) design cost of WPPIS $C_{p}$ [currency]; 2) implementation cost of WPPIS $C_{i s}$ [currency], 3) operation and maintenance cost of WPPIS $C_{e}$ [currency/year], 4) availability of WPPIS $A$ [probability].

The model MKO1_VEPIS_44 establishes the rank of preferences for the alternatives in terms of domination rate in the dimensionless scale $[0,1]$, where 1 is necessarily assigned for the most preferable alternative (only preferable versus others, but not necessarily effective or good working). The model requires from the experts to agree on the same set of criteria and on the same acceptable range [ $\min , \max ]$ of natural values for each criterion. Also it assumes that experts differentiate the significance of criteria and assign to criteria their own weight factors. Since in the preceding investigation (Nemura, 2006) all 3 experts have agreed on the same criteria ranges and assigned rather similar weight factors, it can be regarded as case of concerted expert views. 


\subsection{Normalization of Projected Natural Values of Criteria}

The identity of an alternative is defined and discerned by its projected natural values of criteria, one value per criterion. Certainly, the experts should fully agree on the same projected values. When applying the model MKO1_VEPIS_44 in interactive way on PC, each expert doesn't treat the projected natural values but their utility values $U_{i j}(1)$ and (2). These values are not freely assumed like informal personal estimates of experts. On the contrary, they are obtained as formal results of normalization of projected natural values of criteria.

The normalization expressions are piecewise linear functions. The expression (1) is applied for minimum-targeted criteria $C$ (e.g., frequency of accidents, cost), while (2) for maximum-targeted criteria $A$ (e.g., profit, reliability):

$$
\begin{aligned}
& U_{i j}= \begin{cases}1, & \text { when } C_{i j} \leqslant C_{j}^{\min }, \\
\frac{C_{j}^{\max }-C_{i j}}{C_{j}^{\max }-C_{j}^{\min }}, & \text { when } C_{j}^{\min }<C_{i j}<C_{j}^{\max }, \\
0, & \text { when } C_{i j} \geqslant C_{j}^{\max },\end{cases} \\
& U_{i j}= \begin{cases}0, & \text { when } A_{i j} \leqslant A_{j}^{\min }, \\
\frac{A_{j}^{\min }-A_{i j}}{A_{j}^{\min }-A_{j}^{\max }}, & \text { when } A_{j}^{\min }<A_{i j}<A_{j}^{\max }, \\
1, & \text { when } A_{i j} \geqslant A_{j}^{\max },\end{cases}
\end{aligned}
$$

where $U_{i j} \in[0,1]$ - utility value of projected natural value of criterion $j$ (i.e., $C_{i j}$ or $A_{i j}$ ) of alternative $i$, and $C_{j}^{\min }, A_{j}^{\min }$ and $C_{j}^{\max }, A_{j}^{\max }$ - the lower and upper limits of range (interval) of natural criterion values, respectively. As it follows, $U_{i j}=0$ corresponds to the worst utility, and $U_{i j}=1-$ to the best one. As concerns the reference WPPIS, the $C_{i j}$ in (1) stands for criteria $C_{p}, C_{i s}, C_{e}$ and $A$ in (2) - for the criterion $A$ (availability of WPPIS).

Incidentally, availability $A$ of WPPIS (i.e., its communication alternative) may be found as probability of outage-free operation (Billington, 1996):

$$
A=\frac{T_{\text {out }}}{T_{\text {out }}+T_{\text {rest }}},
$$

where $T_{\text {out }}-$ mean duration of continuous operation of WPPIS between two outages and $T_{\text {rest }}$ - mean duration of restoration of WPPIS, i.e., mean time of outage elimination. As follows from (3), $0 \leqslant \mathrm{~A} \leqslant 1$. Accordingly, the $T_{\text {out }}=1 / \lambda$, where $\lambda$ is the outage intensity of WPPIS. For instance, if $\lambda=5$ year $^{-1}$, then the $T_{\text {out }}=1 / \lambda=0.2$ year $=1752 \mathrm{~h}$. As for restoration time, it can be assumed that $T_{\text {rest }}=2.0 \mathrm{~h}$ and then

$$
A=\frac{1752}{1752+2}=0.99886
$$

As concerns the weights of criteria, there is no doubt whatever that the weight factors $w_{i j}$ of criteria $j, j=1, \ldots, n$ should be balanced for each alternative $i$ so as to comply with the condition $\sum_{j=1}^{n} w_{i j}=1,0 \leqslant w_{i j} \leqslant 1$. 


\subsection{Method of Pair Comparisons}

Method of pair comparisons (Saaty, 1977) is the most natural and plain method for a user. Underlying this method is the comparison of two alternatives in pairs and estimation on how much one alternative is better than another. When the superiority estimates of pair comparisons from the experts are available, mostly the logarithmic least squares estimate procedure is applied to rank the alternatives. The procedure refers to the logarithmic linear model:

$$
\ln a_{i k}=\ln w_{i}-\ln w_{k}+\varepsilon_{i k}, \quad i, k=1,2, \ldots, m,
$$

where $a_{i k}$ - expert's estimate of superiority (in times) of alternative $i$ versus alternative $k$, $\varepsilon_{i k}$ - model's deviation, $w_{i}$ - weight factor for alternative $i, m$ - number of alternatives.

If domination rate $r_{i}$ of the alternative $i$ is defined as

$$
r_{i}=\left(a_{i 1} a_{i 2} \ldots a_{i m}\right)^{1 / m}, \quad k=1, \ldots, m
$$

then a logarithmic least squires estimate will equal to

$$
w_{i} / w_{k}=r_{i} / r_{k}
$$

and the normalized weight factor of alternative $i$ is found:

$$
w_{i}=r_{i} / \sum_{k=1}^{m} r_{k}, \quad i=1,2, \ldots, m
$$

To streamline the application of this method, the simple pair comparisons are often practised. As it appeared, it is rather difficult to obtain data $a_{i k}$ from a single expert when the number of alternatives is rather large. The procedure is run in more easy way when it is assumed that $a_{i k}=e$ if $a_{i k}>0$, and $a_{i k}=1 / e$ if $a_{i k}<0$.

The model MKO1_VEPIS_44 implements the simplified version of the method: it is needed from a user (expert) to indicate only "which one from two should be preferred". As a matter of fact, the response "I don't know" is quite a fair estimate.

\subsection{Method of Pareto Sets}

There have been proposed a lot of methods to find a Pareto set or a subset. Mostly the problem is merely transformed to optimization of a single function. The most simple is the weight factors method (Cohon, 1978) which is embedded into the model MKO1_VEPIS_44:

$$
R_{i}=\sum_{j=1}^{n} w_{j} U_{j}\left(X_{i}\right), \quad X_{i} \in \boldsymbol{X} ; \quad \text { subjected to } \sum_{j=1}^{n} w_{j}=1, \quad w_{j} \geqslant 0
$$


where $R_{i}$ - utility index of alternative $i ; w_{j}$ - weight factor of criterion $j$ (established by an expert); $U_{j}\left(X_{i}\right)$ - utility value of criterion's $j$ projected natural value in alternative $i$; $\boldsymbol{X}$ - the given finite set of alternatives $i$; $n$ - number of criteria. If $\boldsymbol{X}$ is a convex set and the utility values $U_{j}\left(X_{i}\right), j=1, \ldots, n, i=1, \ldots, m$ are concave, the problem's (6) solution $R_{i}$ is a point of Pareto set. Varying the $w_{j}, j=1 \ldots, n$, the problem (6) is resolved and the optimized solutions belonging to Pareto set attained. Such a variation procedure is embedded into the MKO1_VEPIS_44. Its user varies $w_{j}$ and promptly follows the resulting change of $R_{i}$. Concurrently he can follow the changing rank of the alternatives within the Pareto set.

The utility index $R_{i}$ shall be normalized in the following way:

$$
d_{i}=\frac{R_{i}}{\max _{1 \leqslant i \leqslant m} R_{i}}
$$

where $d_{i}$-domination rate of the alternative $i$. Thus the best (most preferred) alternative is always awarded the value 1 of domination rate $d$.

\subsection{Method of Fuzzy Sets}

This method is approached to the Pareto set method and, in addition, provides a possibility to an expert to measure an extent of his uncertainty in the situations when

- an expert feels uncertain in his opinion and estimates;

- lack of information is evident;

- there emerge different opinions of experts within a group.

The method is based on the properties of fuzzy variables with triangular dependence function (Zhang, 1992; Nemura, 2001; Dubois, 1980). According to it, each normalized criterion $U_{j}\left(X_{i}\right)=U_{i j}$ is linked to the fuzzy number $L_{j}\left(X_{i}\right)=L_{i j}$ with triangular dependence function

$$
L_{i j}=\left[L_{i j}^{l}, L_{i j}^{m}, L_{i j}^{u}\right]=\left[10 U_{i j}^{l}, 10 U_{i j}^{m}, 10 U_{i j}^{u}\right],
$$

where $L_{i j}^{l}$ - the lower value of fuzzy number assigned to the utility value of criterion $j$ in alternative $i$ and $L_{i j}^{m}, L_{i j}^{u}$ - the medium and upper values of fuzzy number, respectively.

The characteristic values of $L_{i j}^{l}, L_{i j}^{m}, L_{i j}^{u}$ are set by each expert as value judgments. It shall be noted that all the normalized criterion values $U_{i j} \in[0,1]$ while their fuzzy numbers $L_{i j} \in[0,10]$. The model MKO1_VEPIS_44 calculates the rate of domination $d_{i}$ of alternative $i$ versus others. Each alternative $i$ is described by a fuzzy variable

$$
S_{i}=\sum_{j=1}^{n} L_{i j} w_{j} \otimes\left[\sum_{j=1}^{n} \sum_{i=1}^{m} L_{i j} w_{j}\right]^{-1}, \text { subjected to } \sum_{j=1}^{n} w_{j}=1 .
$$

Here symbol $\otimes$ means the multiplication sign for fuzzy numbers. Also the criterion weights $w_{j}, j=1, \ldots, n$, can be fuzzy triangular numbers. 
The best (most preferred) alternative $i$ is determined by means of domination rate $d_{i}$ over all the rest alternatives $k$ :

$$
d_{i}=\min _{1 \leqslant k \leqslant m ; k \neq i} V\left(S_{i} \geqslant S_{k}\right), \quad i=1, \ldots, m
$$

This rate is a scalar variable. $V\left(S_{i} \geqslant S_{k}\right)$ in (10) is an extent of possibility that fuzzy variable $S_{i}$ is equal to or bigger than $S_{k}$. The detailed expressions $V\left(S_{i} \geqslant S_{k}\right)$ are presented in (Dzemyda, 1994). As stated above for Pareto set method, the best alternative from (9) is normalized to the level of domination rate $d=1$.

If the ranking is performed by the group consisting of $q$ experts, the normalized weight factor $w_{j}^{q}$ of criterion $j$ is calculated as:

$$
w_{j}^{q}=\frac{\frac{1}{q} \sum_{s=1}^{q} w_{j s}}{\sum_{j=1}^{n} \frac{1}{q} \sum_{s=1}^{q} w_{j s}}, \quad j=1, \ldots, n .
$$

Then the normalized fuzzy variable $\bar{S}_{i}$ of alternative $i$ is

$$
\bar{S}_{i}=\sum_{j=1}^{n} \bar{L}_{i j} w_{j}^{q} \otimes\left[\sum_{j=1}^{n} \sum_{i=1}^{m} \bar{L}_{i j} w_{j}^{q}\right]^{-1},
$$

where the criterion's $j$ normalized fuzzy number $\bar{L}_{i j}$ in alternative $i$ is

$$
\bar{L}_{i j}=\left[\frac{1}{q} \sum_{s=1}^{q} L_{i j s}^{l}, \frac{1}{q} \sum_{s=1}^{q} L_{i j s}^{m}, \frac{1}{q} \sum_{s=1}^{q} L_{i j s}^{u}\right] .
$$

Similarly to (10), the summarized mean domination rate $\bar{d}_{i}$ of alternative $i$ as determined by $q$ experts is calculated as

$$
\bar{d}_{i}=\min _{1 \leqslant k \leqslant m ; k \neq i} V\left(\bar{S}_{i} \geqslant \bar{S}_{k}\right), \quad i=1, \ldots, m .
$$

\subsection{Findings of Previous Investigation}

As it was found in previous investigation (Nemura, 2006), the same ranks of preferences were obtained by experts with concerted (i.e., not conflicting) views. Furthermore, each expert found the same ranks by all three methods applied (as stated above). The consolidated (summarized within expert group) rank of preferences had the following rates of domination:

- top preference to seamless topology (3rd alternative) $-\bar{d}_{3}=1.00$;

- second preference to centralized topology (1st alternative $)-\bar{d}_{1}=0.78$;

- least preference to mixed topology (2nd alternative) $-\bar{d}_{2}=0.70$. 


\section{New Investigation of the Reference Alternatives of WPPIS}

New experts have been invited to assess the same (reference) alternatives of WPPIS as in previous investigation. They received the task to compare them using the multi-criterion approach (1)-(14) embedded in the same model MKO1_VEPIS_44. The deliverables were expected to be the ranks of preferences of the alternatives suitable for purpose of decision support.

\subsection{The Identity of Reference Alternatives of WPPIS in Preceding and Current Investigations}

To ensure the comparability with the preceding investigation (Nemura, 2006), the same reference alternatives of WPPIS have been taken for current analysis: centralized topology Cent (1st alternative), mixed topology Mix (2nd alternative) and seamless topology Seam (3rd alternative). Distinction of each alternative is defined by projected natural values of criteria (projected parameter values) as presented in Table 1.

In addition to these, say, endogenous, initial data, the same number of experts (it is an exogenous parameter) was held on (three experts).

\subsection{Conflicting Views of Experts on Criteria}

Primarily, the experts were offered to adopt the same acceptable ranges of natural values of criteria as it were in the previous investigation. Nevertheless, two experts E1, E2 established their own acceptable ranges for criteria $C_{p}, C_{i s}, C_{e}$, while the third E3 relied on the previous ranges agreed by the preceding expert group. Considering the criterion $A$, all three experts acknowledged the acceptability of its former range.

An individual view of each expert consisted of 2 components: 1) viewpoint on acceptable ranges of criteria (as stated above) and 2) viewpoint on criterion weight factors. Contrary to current investigation, the individual views in preceding investigation contained only the second viewpoint.

Viewpoints on the acceptable ranges for criteria $C_{p}, C_{i s}, C_{e}$ as put forward by experts E1 and E2 appeared to be not only different but even quite opposite. Also opposite viewpoints (by all three experts) were expressed on criterion weight factors. Moreover, as it

Table 1

Projected natural values of criteria in reference alternatives of WPPIS

\begin{tabular}{lccc}
\hline Criterion & Cent & Mix & Seam \\
\hline$C_{p}[\mathrm{LT}]^{*}$ & $0.125 \times 10^{6}$ & $0.18 \times 10^{6}$ & $0.19 \times 10^{6}$ \\
$C_{i s}[\mathrm{LT}]$ & $2.55 \times 10^{6}$ & $2.9 \times 10^{6}$ & $2.85 \times 10^{6}$ \\
$C_{e}[\mathrm{LT} / \mathrm{y}]$ & $0.13 \times 10^{6}$ & $0.125 \times 10^{6}$ & $0.12 \times 10^{6}$ \\
$A[$ probability $]$ & 0.999 & 0.9992 & 0.9995 \\
\hline
\end{tabular}

* LT denotes Lithuanian currency Litas 
finally turned out, the experts formed rather consistent but hardly compatible system of individual views. These views can be defined as follows:

View-E1: "Least cost is precondition and initial cost is of crucial importance".

View-E2: "Large cost is unavoidable and O\&M cost is of crucial importance".

View-E3: "Medium-size cost is possible and availability is of crucial importance".

The elements of individual views are presented in Table 2. These elements might be regarded as exogenous initial data.

Individual view of E1. The acceptable ranges of cost criteria $C_{p}, C_{i s}, C_{e}$ should be established in the low cost intervals. It means that, whatever to be the situation in the market of WPPIS, the WPP owners are recommended to aim at least-cost alternative and assess the higher projected cost values (beyond the range) as unsatisfactory. The major weights shall be assigned to the initial cost of the alternative, i.e., to the design cost (criterion $C_{p}$ ) and implementation $\operatorname{cost}$ (criterion $C_{i s}$ ). The relatively small weight of availability $(0.15$, Table 2) was based on the attitude that availability of modern WPPIS is sufficiently high and needs no "reinforcement" by larger weight factor (similarly to, say, robustness of a router, which is of crucial significance for WPPIS, but being highly failure-resistant, can be excluded from criterion list of WPPIS as quite "matured" feature).

Individual view of E2. The acceptable ranges of cost criteria $C_{p}, C_{i s}, C_{e}$ should be established in the high cost intervals. It means that, whatever to be the situation in the market of WPPIS, the WPP owners might hardly expect to avoid the large cost. The major weight shall be assigned to the permanent cost, i.e., to the O\&M cost (criterion $\left.C_{e}\right)$. The relatively small weight of availability $(0.13$, Table 2$)$ was based on the same attitude as that of E1.

Individual view of E3. It is realistic to establish the acceptable ranges of cost criteria $C_{p}, C_{i s}, C_{e}$ in the medium-size cost intervals. The items of WPPIS currently or soon provided to market are supposed to get into those ranges (i.e., their projected values do).

Table 2

Elements of individual views of experts on criteria of WPPIS

\begin{tabular}{lccc}
\hline Element & View-E1 & View-E2 & View-E3 \\
\hline Acceptable range of criterion $C_{p}$ & {$[0.08,0.15]$} & {$[0.16,0.25]$} & {$[0.12,0.2]$} \\
{$\left[C_{p}^{\text {min }}, C_{p}^{\text {max }}\right]\left(10^{6} \mathrm{LT}\right)$} & & & \\
Acceptable range of criterion $C_{i s}$ & {$[2.2,2.75]$} & {$[3.0,3.5]$} & {$[2.5,3.0]$} \\
{$\left[C_{i s}^{\text {min }}, C_{i s}^{\text {max }}\right]\left(10^{6} \mathrm{LT}\right)$} & & & \\
Acceptable range of criterion $C_{e}$ & {$[0.08,0.12]$} & {$[0.12,0.18]$} & {$[0.11,0.14]$} \\
{$\left[C_{e}^{\text {min }}, C_{e}^{\text {max }}\right]\left(10^{6} \mathrm{LT}\right)$} & & & \\
Acceptable range of criterion $A$ & {$[0.9985,0.9996]$} & {$[0.9985,0.9996]$} & {$[0.9985,0.9996]$} \\
{$\left[A^{\text {min }}, A^{\text {max }}\right]$ (probability) } & 0.2 & 0.07 & 0.07 \\
Weight factor $w_{C p}$ & 0.4 & 0.2 & 0.13 \\
Weight factor $w_{C i s}$ & 0.25 & 0.60 & 0.20 \\
Weight factor $w_{C e}$ & 0.15 & 0.13 & 0.60 \\
Weight factor $w_{A}$ & &
\end{tabular}


The major weight shall be assigned to availability (0.60, Table 2), contrary to the attitudes of E1 and E2. It is assumed that such a higher weight will act like an instrument to heighten the availability of WPPIS.

Hence, the View-E1, View-E2 and View-E3 can be considered as conflicting views.

\subsection{The Criterion Utility Values and Uncertainties}

Contrary to previous investigation when the criterion utilities were the same for all the experts, the application of the formulae (1), (2) lead to the individual sets of utilities in the current investigation. It came out from the difference of values of $C_{j}^{\min }, C_{j}^{\max }$, $j=1,2,3$ for each expert. This is the reason why the utilities $U_{i j}=0$ and $U_{i j}=1.0$ appeared rather frequently in the Tables 3-5: the projected natural values didn't get into the acceptable range of criterion values.

By the Fuzzy set method (8)-(10) the experts evaluated their uncertainty to their own initial data (acceptable ranges of criterion natural values and weight factors) by ascription

Table 3

Criterion utilities $U_{i j}$ of projected values in accordance with the View-E1

\begin{tabular}{cccc}
\hline Criterion & Cent & Mix & Seam \\
\hline$C_{p}$ & 0.4286 & 0 & 0 \\
$C_{i s}$ & 0.3636 & 0 & 0 \\
$C_{e}$ & 0 & 0 & 0 \\
$A$ & 0.4545 & 0.6364 & 0.9091 \\
\hline
\end{tabular}

Table 4

Criterion utilities $U_{i j}$ of projected values in accordance with the View-E2

\begin{tabular}{clll}
\hline Criterion & Cent & Mix & Seam \\
\hline$C_{p}$ & 1.000 & 0.7778 & 0.6667 \\
$C_{i s}$ & 1.000 & 1.000 & 1.000 \\
$C_{e}$ & 0.8333 & 0.9167 & 1.000 \\
$A$ & 0.4545 & 0.6364 & 0.9091 \\
\hline
\end{tabular}

Table 5

Criterion utilities $U_{i j}$ of projected values in accordance with the View-E3

\begin{tabular}{clll}
\hline Criterion & Cent & Mix & Seam \\
\hline$C_{p}$ & 1.000 & 0.2500 & 0.1250 \\
$C_{i s}$ & 0.9000 & 0.2000 & 1.000 \\
$C_{e}$ & 0.3333 & 0.5000 & 1.000 \\
$A$ & 0.4545 & 0.6364 & 0.9091 \\
\hline
\end{tabular}


Table 6

Fuzzy numbers $L_{i j}^{l}, L_{i j}^{m}, L_{i j}^{u}$ as assigned by E1 to the criterion utilities $U_{i j}$ of Table 3

\begin{tabular}{cccc}
\hline Criterion & Cent & Mix & Seam \\
\hline$C_{p},\left[L^{l}, L^{m}, L^{u}\right]$ & {$[4,5,7]$} & {$[1,1,2]$} & {$[1,1,2]$} \\
$C_{i s}\left[L^{l}, L^{m}, L^{u}\right]$ & {$[2,4,5]$} & {$[1,1,2]$} & {$[1,1,2]$} \\
$C e\left[L^{l}, L^{m}, L^{u}\right]$ & {$[1,1,1]$} & {$[1,1,2]$} & {$[1,1,2]$} \\
$A\left[L^{l}, L^{m}, L^{u}\right]$ & {$[2,5,7]$} & {$[4,6,9]$} & {$[7,9,10]$} \\
\hline
\end{tabular}

Table 7

Fuzzy numbers $L_{i j}^{l}, L_{i j}^{m}, L_{i j}^{u}$ as assigned by E2 to the criterion utilities $U_{i j}$ of Table 4

\begin{tabular}{cccc}
\hline Criterion & Cent & Mix & Seam \\
\hline$C_{p},\left[L^{l}, L^{m}, L^{u}\right]$ & {$[10,10,10]$} & {$[6,7,9]$} & {$[5,7,8]$} \\
$C_{i s}\left[L^{l}, L^{m}, L^{u}\right]$ & {$[9,10,10]$} & {$[9,10,10]$} & {$[9,10,10]$} \\
$C e\left[L^{l}, L^{m}, L^{u}\right]$ & {$[7,8,9]$} & {$[9,9,10]$} & {$[9,10,10]$} \\
$A\left[L^{l}, L^{m}, L^{u}\right]$ & {$[3,5,5]$} & {$[5,6,8]$} & {$[5,9,9]$} \\
\hline
\end{tabular}

Table 8

Fuzzy numbers $L_{i j}^{l}, L_{i j}^{m}, L_{i j}^{u}$ as assigned by E3 to the criterion utilities $U_{i j}$ of Table 5

\begin{tabular}{cccc}
\hline Criterion & Cent & Mix & Seam \\
\hline$C_{p},\left[L^{l}, L^{m}, L^{u}\right]$ & {$[9,9,10]$} & {$[1,3,4]$} & {$[1,1,2]$} \\
$C_{i s}\left[L^{l}, L^{m}, L^{u}\right]$ & {$[7,9,10]$} & {$[1,2,3]$} & {$[1,3,4]$} \\
$C e\left[L^{l}, L^{m}, L^{u}\right]$ & {$[2,3,4]$} & {$[4,5,7]$} & {$[6,7,7]$} \\
$A\left[L^{l}, L^{m}, L^{u}\right]$ & {$[3,5,6]$} & {$[5,6,7]$} & {$[8,9,10]$} \\
\hline
\end{tabular}

of fuzzy numbers $L_{i j}^{l}, L_{i j}^{m}, L_{i j}^{u}, j=1, \ldots, 4, i=1,2,3$, to the criterion utility values (Table 3-5). These numbers are presented in Tables 6-8, respectively.

It might be seen that the extent of uncertainty - range $\left[L^{l}, L^{u}\right]$ - was rather small for all criteria and all experts. It means that experts regarded their acceptable ranges of criteria as fairly established.

\subsection{Solutions of the Investigation}

The results of assessment of preferences are presented in Table 9. The solutions are grouped by a multi-criterion analysis method and an expert. The ranks of preferences are arranged in vertical columns.

It may be concluded from the Table 9 that each method lead to the same rank of multicriterion preferences within View-E1 and View-E2. In case of View-E3, there is a certain divergence, because the pair comparison generated an inverse succession of the second and least preferences as the Pareto sets did. Between the views, the ranks derived by the summarized methods (the last row Summarized methods in Table 9) vary to significant 
Table 9

Ranks of multi-criterion preferences of alternatives of WPPIS

\begin{tabular}{|c|c|c|c|}
\hline \multirow{2}{*}{ Method } & \multicolumn{3}{|c|}{ Rates of domination $d_{i}$} \\
\hline & View-E1 & View-E2 & View-E3 \\
\hline \multirow[t]{3}{*}{ Pair comparison } & Cent 1.00 & Seam 1.00 & Seam 1.00 \\
\hline & Seam 0.50 & Mix 0.50 & Mix 0.50 \\
\hline & Mix 0.25 & Cent 0.00 & Cent 0.00 \\
\hline \multirow[t]{3}{*}{ Pareto sets } & Cent 1.00 & Seam 1.00 & Seam 1.00 \\
\hline & Seam 0.61 & Mix 0.90 & Cent 0.74 \\
\hline & Mix 0.49 & Cent 0.84 & Mix 0.70 \\
\hline \multirow[t]{3}{*}{ Fuzzy sets } & Cent 1.00 & Seam 1.00 & Seam 1.00 \\
\hline & Seam 0.70 & Mix 0.77 & Cent 0.78 \\
\hline & Mix 0.61 & Cent 0.64 & Mix 0.78 \\
\hline \multirow[t]{3}{*}{ Summarized methods } & Cent 1.00 & Seam 1.00 & Seam 1.00 \\
\hline & Seam 0.61 & Mix 0.72 & Cent 0.60 \\
\hline & Mix 0.45 & Cent 0.49 & Mix 0.50 \\
\hline
\end{tabular}

extent. Such an effect might be pointed to conflicting nature of expert views, whereas the concerted views (as in the preceding investigation) brought to nearly the identical ranks (Nemura, 2006). Specifically, the 3rd alternative (Seam) of WPPIS was awarded twice the top preference (View-E2 and View-E3). Nevertheless, this priority is challenged by 1 st alternative (Cent) within View-E1.

Similarly, the least preference was not tagged to one single alternative. The 2nd alternative (Mix) was found twice to be the least preferred (View-E1 and View-E3) followed by the 1st alternative (Cent) with one time (View-E2).

A preference of the 1st alternative (Cent) is mostly dispersed: it "floats" across the ranks of preferences in columns View-E1, View-E2 and View-E3 (Table 9) taking all positions (top, least and second), respectively.

The consistency of each individual expert view can be confirmed by the fact that Fuzzy numbers exerted rather a moderate impact on the ranks derived by the Pareto sets. Specifically, the ranks have been found the same both by Pareto sets and Fuzzy sets, but with different rates of domination $d_{i}$. Moreover, within View-E3, this impact looks more appreciable, as Fuzzy numbers raised the 2nd alternative (Mix) to the position of 1st alternative (Cent): both alternatives are equally preferred owing to the same rate of domination rate $d_{i}=0.78$.

The consolidated rank of multi-criterion preferences (as an average of individual views View-E1, View-E2 and View-E3) can be found from the ranks by summarized methods. This rank is the same as in the case of concerted expert views (see section 3.6), only with slight differences in rates of domination:

- top preference to Seam (3rd alternative) $-\bar{d}_{3}=1.00$;

- second preference to Cent (1st alternative) $-\bar{d}_{1}=0.76$;

- least preference to Mix (2nd alternative) $-\bar{d}_{2}=0.68$. 
Table 10

Assignment of grades $R R_{i}$ for the rates of domination $d_{i}$ from ranks "Summarized methods" in Table 9

\begin{tabular}{cccc}
\hline \multirow{2}{*}{ Alternative of WPPIS } & \multicolumn{3}{c}{ Rate of domination $d_{i}$} \\
\cline { 2 - 4 } Crade $R R_{i}{ }^{*}$ & View-E1 & View-E2 & View-E3 \\
\hline Cent & $\frac{1.00}{1}$ & $\frac{0.49}{3}$ & $\frac{0.60}{2}$ \\
Mix & $\frac{0.45}{3}$ & $\frac{0.72}{2}$ & $\frac{0.50}{3}$ \\
Seam & $\frac{0.61}{2}$ & $\frac{1.00}{1}$ & $\frac{1.00}{1}$ \\
\hline
\end{tabular}

* The following rule of assignment is applied: $R R_{i}=1$ for $d_{i} \in[0.8,1.0]$, $R R_{i}=2$ for $d_{i} \in[0.60,0.799]$ and $R R_{i}=3$ for $d_{i} \in[0.40,0.599]$.

Neither the ranks by summarized methods nor the consolidated rank disclose the degree of differences or coincidence of the conflicting experts wiews. To measure it in quantifiable scale, the Kendall concordance coeffcient $W$ can be applied. It ranges in $[0,1]$. The close-to-zero values point to independence/opposition of individual views, whereas close-to-unit values mean dependent/identical views. The $W$ is found through the substitution of rates of domination by the arbitrary grades (ranks) and applying the following formulas (Čekanavičius, 2002):

$$
\begin{aligned}
& W=\frac{12 \tilde{S}}{g^{2}\left(m^{3}-m\right)}, \\
& \tilde{S}=\sum_{i=1}^{m}\left(\tilde{R}_{i}-\frac{g(m+1)}{2}\right),
\end{aligned}
$$

where $\tilde{R}_{i}$ - average grade of the alternative $i ; m$-number of alternatives; $g$ - number of grades (number of experts). This average was derived from individual expert grades $R R_{i}$ (Table 10).

According to (15) and (16), the Kendall concordance coefficient was found to be $W=0.44$. Accordingly, the correlation of experts views is rather weak, but, anyway, appreciable. Hence, the conflicting expert views reveal themselves to be a bit dependent rather than totally discordant.

\section{Conclusions}

1. Multi-criterion assessment of preferences for communication alternatives of wind power park information system based on conflicting expert views on criteria (primarily, on their ranges on natural values) resulted in the same consolidated (averaged) rank of preferences as it was obtained on the base of concerted expert 
views: top preference to seamless topology (3rd alternative), second preference to centralized topology (1st alternative) and least preference to mixed topology (2nd alternative). Nevertheless, contrary to concerted expert case, the obtained ranks of preferences were rather dispersed across the individual conflicting expert views.

2. When introduced into the multi-criterion preferences assessment problem, the conflicting views on ranges of criterion natural values may be a good means to check the robustness of previous solutions (ranks of preferences) found by the concerted expert views.

3. If ranks of preferences by individual conflicting expert views cannot be averaged into a consolidated rank, it is recommended to group the views into two or more sets (clusters), each containing non-antagonistic (compatible) views on the alternatives, with their own ranks of preferences. Chances or probabilities of occurrence of each set (cluster) of expert views should be evaluated or, at least, discussed.

\section{References}

Billington, R., and R.N. Allan (1996). Reliability Evaluation of Power Systems. 2nd. ed. Plenum Press, New York.

Čekanavičius, V., and G. Murauskas (2002). Statistics and its Applications. TEV, Vilnius (in Lithuanian).

Cohon, J.L. (1978). Multiobjective Programming and Planning. Academic Press, New York.

Dubois, D., and H. Prade (1980). Fuzzy Sets and Systems. Theory and Applications. Academic Press, New York.

Dzemyda, G., and V. Šaltenis (1994). Multiple criteria decision support system: methods, user's interface and applications. Informatica, 5(1-2), 31-42.

Nemura, A., and D. Balakauskas (2001). Multiobjective analysis of alternatives of updating the automated dispatch control of the unified power system of the Baltic states. Energetika, 1, 3-9.

Nemura, A., and A. Klementavičius (2006). Multiple-criterion analysis of communication variants of information system of wind power park. In A. Navickas (Ed.), Proceedings of International Conference Electrical and Control Technologies-2006. Technologija, Kaunas. pp. 21-26.

Saaty, T.L. (1977). A scaling method for priorities in hierarchical structures. J. Math. Psychology, 15, $234-281$. Zhang, Li Li, and Chang Da Yong (1992). Extent analysis and synthetic decision. In Support Systems for Decision Negotiation Processes, Preprints of IFAC/IFORS/IIASA/TIMS Workshop, Warsaw, 2. pp. 633639. 
A. Nemura graduated from Kaunas Polytechnic Institute in 1951. He received his PhD degree in engineering sciences from the same institute in 1957 and his doctor habilitus degree in engineering sciences from Latvian Academy of Sciences in Riga, Latvia in 1973. He is a corresponding member of Lithuanian Academy of Sciences since 1962 and currently is a member of Electronics and Informatics Section in Division of Engineering Sciences of the Academy. Professor since 1982. He is a State Prize Laureate of former Soviet Lithuania for the development and application of identification methods (with coauthors, 1980). His research interests are centred on adaptive control theory, identification methods, fuzzy sets theory, mathematical modelling, optimization and control of power systems.

A. Klementavičius received his dipl. eng. degree from Kaunas Polytechnic Institute, Lithuania, in 1979. He was conferred a PhD degree in engineering sciences by Lithuanian Energy Institute and Kaunas University of Technology in 1999. Currently he is a research associate in the Laboratory of System Control and Automation in Lithuanian Energy Institute. His major research interests include power system control, operation of electrical networks and multi-criterion analysis.

\title{
Daugiakriterinis pirmenybès nustatymas vẻjo elektriniu parko informacinių sistemu komunikacijos alternatyvoms
}

\author{
Antanas NEMURA, Arturas KLEMENTAVIČIUS
}

Straipsnyje aprašomas daugiakriteriniu analizès metodu taikymas IEC 61400-25 standarta atitinkančiu vejjo elektriniu parko informacinių sistemu komunikacijos alternatyvụ tyrimui ir palyginimui. Palyginimas grindžiamas alternatyvos daugiakriterine pirmenybe, kuri matuojama dominavimo koeficientu. Etaloninėmis alternatyvomis pasirinktos centralizuotoji, mišrioji ir vientisoji komunikacijos topologijos. Nagrinèjamos pagrindinès šiu topologiju savybės ir daugiakriterinès analizès metodika, susidedanti iš porinių palyginimu, Pareto aibès ir neryškių skaičiu aibės metodụ. Parodyta, kad aprašomas tyrimas yra tụ pačių etaloninių alternatyvų ankstesnio tyrimo plètinys. Nustatyta, kad pereinant nuo santykinai darnių ekspertu požiūrių, kaip ankstesniame tyrime, prie konfliktinių ekspertu požiūrių, kaip aprašomame tyrime, ankstesnio tyrimo sprendinys yra atsparus prieštaringiems ekspertu vertinimams ir išlieka nepakitęs - gaunama ta pati alternatyvų pirmenybiu eilè, kurios viršuje yra vientisoji komunikacijos topologija. 